\title{
Determination of optimum parameters for surface roughness in CNC turning by using GRA-PCA
}

\author{
Suneel Kumar Rathore ${ }^{1 *}$, Jyoti Vimal ${ }^{2}$, Dinesh K. Kasdekar ${ }^{3}$ \\ 1,2,3 Department of mechanical Engineering, Madhav Institute of Technology and Science, Gwalior (M.P) - 474005, India \\ "Corresponding Author: e-mail:rathore.suneel8@gmail.com, Tel+91-7974100577
}

\begin{abstract}
In the current research, the $\mathrm{CNC}$ turning operation was implemented by employing the $\mathrm{L}_{16}$ orthogonal arrays on the AA 6463 material, while the impact of the CNC turning process parameters, for instance, the feed rate, spindle speed, depth-of-cut, and coolant (dry and wet condition) are examined with a focus on two output objectives, Ra and Rz. The designed investigational outcomes are employed in GRA while the weights of the responses are calculated by using PCA. The outcome of confirmation trials exposes that GRA joined with PCA can excellently be employed to achieve the best grouping of turning factors. The output accomplishment measures viz., roughness of finished surface are estimated by defining grey relational grade and then the noteworthy contribution of factors are ascertained by ANOVA. In this examination, it was discovered that the generally significant process factor is the coolant, afterward feed rate, spindle speed and depth-of-cut on the selected response parameters.
\end{abstract}

Keywords: CNC Turning, Grey relational analysis, Principal component analysis, ANOVA.

DOI: http://dx.doi.org/10.4314/ijest.v10i2.5

\section{Introduction}

The industrial production is a non-stop challenge for succeeding in advanced productivity and superiority of goods to maintain competitiveness. The preferred profile, size as well as finished ferrous and non-ferrous materials are predictably created by the turning operation, the preformed blanks by means of the support of cutting tools, which progressed beyond the work-piece of a machine tool. Benardos and Vosniakos (2007) states that turning is a vital, far and wide utilised machining procedure in manufacturing systems. It is a noteworthy and broadly utilised machining process in engineering productions. Boothroyd and Knight (1989) studied that in turning operation, the cutting conditions such as SS, FR, DoC, features of tools, coolant and work piece materials etc. affect the procedure efficiency and features. Performance estimation of CNC turning is established on the response parameter like tool wear, SR, tool life, MRR, and power consumption etc. Chinchanikar and Choudhury (2014) presents detailed literature review on machining of hardened steels using coated tools, studies are related with hard turning, numerous cooling methods and tries to model machining performances, for giving proper attention to researcher works. Davim (2003) reported that the high investment price of CNC machine tool demands its effective usage for fast profit of investment. Yuan et al. (2014) studied the three dimensional system approaches by raising manufacturing sustainability concerns from pollution avoidance point-of-respect. Liu et al. (2014) using abrasive water jet tried to scrutinize the impact of working parameters on depth-ofpenetration and SR in the turning of alumina ceramics.

Arbizu and Luis (2003) mentioned that SR is the serious quality pointer for machined surfaces. A superiority turning surface could cause enhancement in strength behavior, for instance, thermal resistance and aesthetics, clean ability, coefficient of friction, fatigue strength, wear rate, assembly tolerance, corrosion resistance etc, with rise in the process parameters, the cutting temperature rises. This is disadvantages to both the product and the tool as it leads to dimensional by thermal distortion, spoils the machined surfaces by persuading thermal effects and built-up-edge development and damages the tool acuteness and vibration. So, the choice of suitable process parameters performs an important character in the efficiency, effectiveness and whole economy of industries by machining to attain these purposes (higher MRR, lower SR and product quality). In turning, parameters, for instance, 
cutting speed, FR and DoC affects surface finish. Groover, (1966) analyses that appropriate cutting parameters are resolute based on practices or by use of a handbook which does not promise optimal performance. Kaladhar et al. (2010) used AISI 202 austenitic stainless as material for research work, full factorial design is used to find best combination of the machining parameters like cutting speed, FR, DoC and nose radius to attain the minimum SR also predictive models obtained for SR.

Several processes and their comparative parameters have been optimized employing the diverse statistical tools, for instance, the RSM, Taguchi scheme, GRA, etc. Rooted in the final response objective these procedures are adopted. Multiple objective optimization procedures are chosen for response variables with different objectives. For example, Kasman (2013) used Taguchibased GRA approach to maximize the tensile strength and elongation of FS welded butt joints. Alagarsamy et al. (2016) perform multi objective optimization of SR and MRR in turning of AA 1040 steel have used GRA and find that cutting speed is the most manipulating parameter affecting joint GRG followed by DoC and FR. Tzeng et al. (2009) used GRA to achieve optimization of turning processes with multiple performance characteristics, for instance, roughness maximum, roughness average, and roundness. The depth-ofcut was recognized to be the most manipulating parameter affecting the GRG followed by feed rate and cutting speed. Nian et al. (1999) used synchronized optimization of multi-responses, Taguchi normalized quality loss function and Lin et al. ( 2004) studied that the grey rooted Taguchi approached have been generally employed in turning and Haq et al. (2008) significantly upgraded through this method. Jeyapaul et al. (2005) investigate, GRA based on grey system theory could be adopted for resolving the complicate interrelationships in the company of the several responses. Through grey analysis, a GRG is favorably defined as an indicator of the numerous accomplishment features for assessment. In recent years, GRA turns out to be a dominant implement to examine the procedures by means of several accomplishment features.

Weighted signal-to-noise ratios, multiple response signal-to-noise ratios and PCA are methods for weighting the characteristic quality for multi-objective processes. Siddiquee et al. (2010); Lu (2009); and Huang and Liao (2003) usage a PCA methodology to institute the distinctiveness quality for each responses. PCA conserves the initial information as much as feasible through making straightforward the several correlated variables into a few uncorrelated and independent principal components. Su \& Ton (1997) and Antony (2002) attempted to integrate Taguchi approach by means of PCA. Latter on Liao (2006); Wu and Chyu (2006); Kasdekar and Parashar (2017) suggested approaches rooted in the foundation of weighted principal components. Ribeiro et al. (2010) has a synchronized optimization of correlative multiple response and used score vector of the first principal component developed from PCA on responses to find best conditions by RSM. Routara and Mohanty (2010) performed PCA on normalized outcomes to calculate the multi-response performance index as a weighted summation of PC values. This research work put forward a hybrid multiobjective optimization method to regulate the objectives for the initial reactions, decrease dimensions and to eliminate the correlation between the multiple responses. This tactic put forward is termed the technique of GRA-PCA.

\section{Literature Review}

Elucidates the work done by previous researchers

Table 1: Summary of research papers

\begin{tabular}{|c|c|c|c|}
\hline References & Material & Input Parameter & Output Parameter \\
\hline $\begin{array}{l}\text { Heidari et al. } \\
2017\end{array}$ & porous carbon & $\begin{array}{l}\text { feed rate }(25,50,75,100 \mathrm{~mm} / \mathrm{min}) \text {, cutting speed }(30,60,90, \\
120 \mathrm{~m} / \mathrm{min}) \text { and depth-of-cut }(0.2,0.4,0.6,0.8 \mathrm{~mm})\end{array}$ & SR \\
\hline $\begin{array}{l}\text { Salimiasl et al. } \\
2016\end{array}$ & AISI 4140 steel & $\begin{array}{c}\text { cutting speeds }(110,135,160 \mathrm{~m} / \mathrm{min} .), \quad \text { feed rates } \\
(0.17,0.22,0.27 \mathrm{~mm} / \mathrm{rev} .) \text { and cutting depths }(0.75,1.25,1.75 \mathrm{~mm})\end{array}$ & Cutting force \\
\hline $\begin{array}{l}\text { Guesser et al. } \\
2016\end{array}$ & grey cast iron & $\begin{array}{c}\text { speed }(400,700,1200,1400 \mathrm{~m} / \mathrm{min}, \text { feed }(0.2 \mathrm{~mm} / \mathrm{rev} \text { and depth- } \\
\text { of-cut }(2 \mathrm{~mm})\end{array}$ & $\mathrm{Ra}, \mathrm{Ry}$ and $\mathrm{Rz}$ \\
\hline Das et al. 2016 & AISI H13 & $\begin{array}{c}\text { Cutting speed }(120,180,240 \mathrm{~m} / \mathrm{min} .), \text { feed rate }(0.1,0.20 \\
.32 \mathrm{~mm} / \mathrm{rev} .) \text { and depth-of-cut }(0.3,0.5,0.7 \mathrm{~mm} .)\end{array}$ & $\begin{array}{c}\text { Tool wear, SR and } \\
\text { MRR }\end{array}$ \\
\hline $\begin{array}{l}\text { Senthilkumar, et } \\
\quad \text { al. } 2016\end{array}$ & AISI D2 Steel & $\begin{array}{c}\text { Cutting Speed }(253,281,309,338 \\
\mathrm{m} / \mathrm{min}), \text { Feedrate }(0.203,0.279,0.356,0.432 \mathrm{~mm} . / \mathrm{rev} .) \text {, Depth-of- } \\
\text { Cut }(0.3,0.4,0.5,0.6 \mathrm{~mm}) \text {, Tool Coating Material (TiAlN TiCN } \\
\text { TiN, Uncoated) }\end{array}$ & $\begin{array}{l}\text { Tool Wear, Roughness } \\
\text { on finished Surface and } \\
\text { MRR }\end{array}$ \\
\hline $\begin{array}{l}\text { Chaurasia et al. } \\
2016\end{array}$ & AA 6061 T6 & $\begin{array}{c}\text { Cutting speed }(120,180,240 \mathrm{~m} / \mathrm{min} .) \text {, feed rate }(0.1,0.20 \\
.32 \mathrm{~mm} / \mathrm{rev} .) \text { and depth-of-cut }(0.3,0.5,0.7 \mathrm{~mm} .)\end{array}$ & MRR \\
\hline $\begin{array}{l}\text { Ranganath and } \\
\text { Mishra et al. } \\
2015\end{array}$ & AA 6061 & $\begin{array}{c}\text { Spindle Speed (500, 550, 600rpm.), DOC }(0.10,0.20,0.30 \mathrm{~mm}) \\
\text { Feed }(0.20,0.24,0.28 \mathrm{~mm} / \mathrm{rev} .)\end{array}$ & SR \\
\hline $\begin{array}{l}\text { Raykar et al. } \\
2015\end{array}$ & $\mathrm{Al} 7075$ & $\begin{array}{c}\text { Type of Insert(Uncoated, Coated) } \\
\text { Condition (Wet/Dry) } \\
\text { Cutting Speed }(200,285,370 \mathrm{~m} / \mathrm{min}) \\
\text { Feed } 0.1,0.2,0.3(\mathrm{~mm} / \mathrm{rev}) \\
\text { Depth-of-Cut }(0.1,1.0,1.5 \mathrm{~mm})\end{array}$ & $\begin{array}{l}\text { Roughness parameters } \\
\text { Ra and Rt, Power } \\
\text { Consumption, Cycle } \\
\text { Time and MRR }\end{array}$ \\
\hline
\end{tabular}




\begin{tabular}{|c|c|c|c|}
\hline $\begin{array}{l}\text { Chaurasia et al. } \\
2015\end{array}$ & AA $6061 \mathrm{~T} 6$ & $\begin{array}{l}\text { Cutting speed }(120,180,240 \mathrm{~m} / \mathrm{min} .) \text {, feed rate }(0.1,0.20 \text {, } \\
.32 \mathrm{~mm} / \mathrm{rev} \text {. }) \text { and depth-of-cut }(0.3,0.5,0.7 \mathrm{~mm} .)\end{array}$ & MRR \\
\hline \multicolumn{4}{|c|}{ Table 1 (cont'd): Summary of Research Papers } \\
\hline References & Material & $\begin{array}{l}\text { Input Parameter } \\
\end{array}$ & Output Parameter \\
\hline $\begin{array}{l}\text { Saini and } \\
\text { Pradhan } \\
\text { et al. } 2014\end{array}$ & AA 8011 & $\begin{array}{c}\text { Spindle Speed(1400,1600,1800rpm) Feed }(0.08,0.14,2.0 \\
\mathrm{mm} / \mathrm{rev}) \\
\text { Depth-of-Cut }(0.4,0.8,1.2 \mathrm{~mm})\end{array}$ & SR and MRR \\
\hline $\begin{array}{l}\text { Mukherjee et al. } \\
2014\end{array}$ & SAE 1020 & $\begin{array}{c}\text { Cutting speed }(60,62,64,66,68 \mathrm{~m} / \mathrm{s}), \text { Feed rate } \\
(0.15,0.2,0.25,0.3,0.35 \mathrm{~mm} / \mathrm{rev}) \text { and Depth-of-cut } \\
(0.1,0.15,0.2,0.250 .3 \mathrm{~mm})\end{array}$ & MRR \\
\hline $\begin{array}{l}\text { Singh and } \\
\text { Sodhi } \\
\text { et al. } 2014\end{array}$ & Al-7020 & $\begin{array}{c}\text { Cutting speed }(100,150 \mathrm{~m} / \mathrm{min} .) \text {, Feed }(0.9,0.17 \mathrm{~mm} / \mathrm{rev}) \text {, Depth- } \\
\text { of-cut }(0.5,2.0 \mathrm{~mm})\end{array}$ & SR and MRR \\
\hline $\begin{array}{l}\text { Singarvel et al. } \\
2014\end{array}$ & EN25 Steel & $\begin{array}{c}\text { Coated tools(CVD,PVD) } \\
\text { Cutting speed }(113,179,244 \mathrm{~m} / \mathrm{min}) \text { Feed } \\
(0.10,0.18,0.26 \mathrm{~mm} / \mathrm{rev}) \\
\text { Depth-of-cut }(0.5,1.0,1.5 \mathrm{~mm})\end{array}$ & $\begin{array}{l}\text { SR, Cutting force, } \\
\text { MRR }\end{array}$ \\
\hline
\end{tabular}

\section{Experimental Work}

\subsection{Plan of experiment}

The experimental work was carried out on UNITURN 500 HD (CNC LATHE MACHINE).The maximum SS on this machine is $4000 \mathrm{rpm}$. Half of the trail was performed in dry condition and rest half of the trail is done by using of the coolant. The SR of work piece profile has been evaluated through a Surface Roughness evaluation implement. The Time ${ }^{\circledR} 3100$ (V20150210) is a convenient, self-restricted apparatus for the evaluation of surface smoothness while it is appropriate for employment in workshops and research laboratories. Factors obtainable for surface texture estimation are: Ra and Rz. The constraint estimation and other functions of the appliance are microprocessor based. The outcomes are displayed on LCD display and print out can be taken with an optional printer or Computer for additional outcomes. The flow chart of CNC Turning is shown in Figure 1.
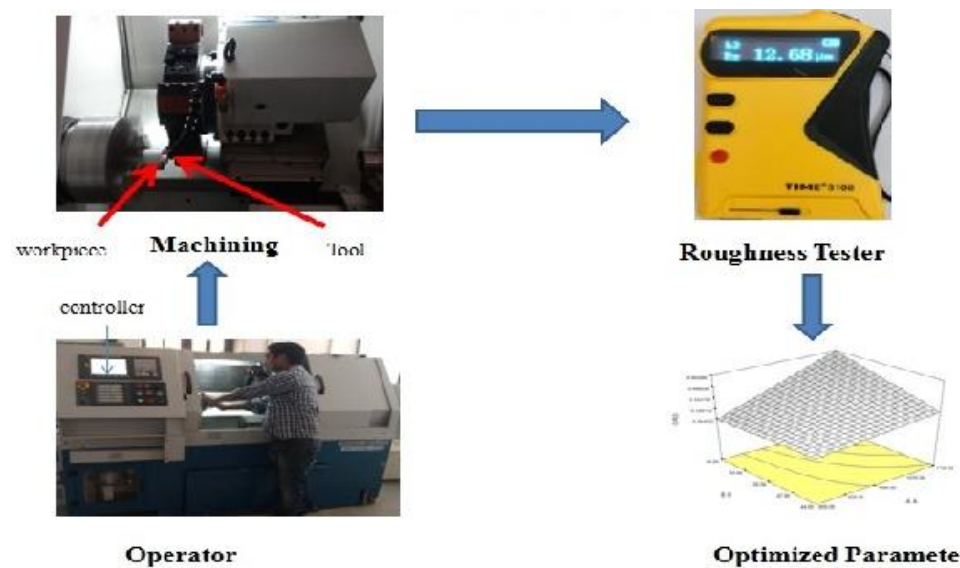

Optimized Parameter

Figure 1: Flow Chart of CNC Turning

\subsection{Work piece material}

In the present experiment we have used AA 6463 for optimization of the SR (Ra,Rz). In the modern industry this is most commonly used extrusion alloy. It also anodizes well, including most common and specialty colors, and is a good strata for painting (as are most alloys). AA 6463 is used in numerous applications such as window manufacturing, patio door, skylight architectural applications, storefront, many automotive and aircraft applications etc . It is found in tubing, pipe, rod bar, extrusion wire, rod, structural shapes etc. A rod of AA 6463 is used for experimental work, the diameter and length of the rod is $50 \mathrm{~mm}$ and $185 \mathrm{~mm}$. The cutting tool (insert) used in this experiment is CNMG 120408 ( $0.8 \mathrm{~mm}$ corner radius). The chemical composition of the work-piece materials are shown in Table 2.

Table 2: Chemical Composition of AA 6463

\begin{tabular}{|c|c|c|c|c|c|c|}
\hline Element & $\mathrm{Si}$ & $\mathrm{Fe}$ & $\mathrm{Cu}$ & $\mathrm{Mn}$ & $\mathrm{Mg}$ & $\mathrm{Al}$ \\
\hline Chemical Composition & 0.870 & 0.168 & 0.027 & 0.510 & 0.438 & Balance \\
\hline
\end{tabular}




\section{Wt. $(\%)$}

\section{Developed methodology}

Experiment was conducted to study the effect of machining parameters; Spindle speed (rpm), Feed rate (mm/min.), Depth-ofcut $(\mathrm{mm})$ and coolant (dry/wet) on $\mathrm{Ra}$ and $\mathrm{Rz}$ on AA 6463 work piece machined on CNC Lathe machine. The design of experiment is generated using Design Expert 6.0.8 Software. Each time the experiment was performed, an optimized set of input parameters were chosen. In this study, the arrangement to conduct the experimental data adopts the full factorial method of experiments with two levels and having a total of 16 runs and actual values as shown in Table 3.

Table 3: Machining parameters and their levels

\begin{tabular}{cccc}
\hline Factors & Unit & \multicolumn{2}{c}{ Levels (Coded Value) } \\
& & $(-1)$ & $(+1)$ \\
Spindle Speed(SS) & Rpm & 850 & 1150 \\
Feed Rate(FR) & mm/min. & 44 & 56 \\
Depth-of-Cut(Doc) & Mm & 0.36 & 0.54 \\
Coolant & - & Dry & Wet \\
\hline
\end{tabular}

\subsection{Optimization steps}

\subsubsection{Grey relational analysis}

The GRA is a judgement-creation scheme rooted in the grey conjecture initially built up through Deng (1989). In the grey philosophy, black signifies a method by means of lacking information, whereas a white method means total information. Nonetheless, the grey relation is the association by means of deficient information and is employed to explain the level of relationship flanked by two categorizations so that the space of two parameters can be evaluated separately. When trials are uncertain or if the trial technique cannot be implemented precisely, grey examination supports to pay back for the absence in statistical regression. Chang et al. (2003) studied that GRA is an adequate way to evaluate the association flanked by progression by means of smaller amount data and can analyses several parameters that can conquer the weaknesses of a statistical approach. Further, it is essential to identify the best noteworthy prominent constraints for CNC Turning. For such practices, GRA, as one of the best authoritative substances of grey theory, has been related at length. Chang et al. (2003) estimated that the standard of GRA is to evaluate the resemblance and level of the smallness amongst parameters rooted in the geometric form of the dissimilar series.

\subsubsection{Data Processing}

When the variety of sequences is huge or the ordinary value is large, the role of factors is ignored. Though, if the factors measured unit, goals and guidelines are different, the GRA might produce improper results. Hence, original trial data must be preprocessed to evade such effects. The data pre-processing is the method of converting the original arrangement to an analogous arrangement. For which, the trial data are normalized in the range of 0 and 1 , the process is called grey relational generating. There are three different kind of data normalizations are usually carried out transferor, whether the 'lower is better' (LB), the 'higher is better' (HB), or 'nominal is the best' (NB). For "larger-the-better 'characteristics, the original sequence can be HB and should be normalized as Fung (2003).

For Higher-the-better (HB),

$$
Z_{i}(k)=\frac{Z_{i}(k)-\min Z_{i}(k)}{\max Z_{i}(k)-\min Z_{i}(k)}
$$

The expectancy is as small as possible for characteristics $\mathrm{Ra}$ and $\mathrm{Rz}$, then original sequence should be normalized as $\mathrm{LB}$

$$
Z_{i}^{*}(k)=\frac{\max Z_{i}(k)-Z_{i}(k)}{\max Z_{i}(k)-\min Z_{i}(k)}
$$

Conversely, if a specific target value is to be achieved, then the original sequence will be normalized by the following equation of NB:

$$
Z_{i}^{*}(k)=\frac{\mid Z_{i}(k)-Z_{o p}(k)}{\max Z_{i}(k)-\min Z_{i}(k)}
$$

where $\mathrm{i}=1,2 \ldots \mathrm{n} ; \mathrm{k}=1,2 \ldots \mathrm{y}, \mathrm{Z}_{\mathrm{i}}(\mathrm{k})$ is the normalized value of the $\mathrm{k}^{\text {th }}$ element in the $\mathrm{i}^{\text {th }}$ sequence; $\mathrm{Z}_{0 \mathrm{p}}(\mathrm{k})$ is the desired value of the $\mathrm{k}^{\text {th }}$ quality characteristic; max $Z_{\mathrm{i}}(\mathrm{k})$ is the largest value of $Z_{\mathrm{i}}(\mathrm{k})$; min $\mathrm{Z}_{\mathrm{i}}^{*}(\mathrm{k})$ is the smallest value of $\mathrm{Z}_{\mathrm{i}}(\mathrm{k})$; n is the number of experiments; and $\mathrm{p}$ is the number of quality characteristics.

\subsubsection{Grey relational coefficient and grey relational grade}


Subsequently as we normalizing the data, usually GRC computed to show the association flanked by the most favourable and genuine normalized experimental results. The grey relational coefficient can be articulated as

$$
\begin{gathered}
\beta_{i}^{k}=\beta\left(Z_{0}(k)-Z_{i}(k)\right)=\frac{\Delta \min +\varepsilon \Delta \max }{\Delta_{o, i}(k)+\varepsilon \Delta \max } \\
\mathrm{i}=1,2 . . \mathrm{n} ; \mathrm{k}=1, \ldots, \mathrm{p},
\end{gathered}
$$

where $\Delta_{0, i}(\mathrm{k})=\left|\mathrm{Z}_{0}(\mathrm{k})-\mathrm{Z}_{\mathrm{i}}(\mathrm{k})\right|$ is the difference of the absolute value, termed the deviation sequence of the reference sequence $\mathrm{Z}_{0}(\mathrm{k})$ and comparability $\mathrm{Zi}(\mathrm{k}) . \varepsilon$ is the distinguishing coefficient or coefficient of identification with the values ranging as $0 \leq \varepsilon \leq 1$. Most of the time, it is fixed at 0.5; therefore, this value is used in this investigation. Deng (1989) affirmed that the quantity 0.5 is by and large used. The purpose of marking out the GRC is to articulate the relative level flanked by the reference series $\mathrm{Z}_{0}(\mathrm{k})$ and the equivalent series $\mathrm{Z}_{\mathrm{i}}(\mathrm{k})$, where $\mathrm{i}=1,2, \ldots, \mathrm{m}$ and $\mathrm{k}=1,2, \ldots, \mathrm{n}$ with $\mathrm{m}=16$ and $\mathrm{n}=4$ in the current research. The grey relational grade $(\mathrm{GRG})$ is a weighted sum of the grey relational coefficients and it is expressed as

$$
\gamma\left(Z_{0}, Z_{i}\right)=\frac{1}{n} \sum_{k=1}^{n} \varepsilon_{k} \beta_{i} \sum_{k=1}^{n} \varepsilon_{k}=1
$$

where $\varepsilon_{\mathrm{k}}$ signifies the weighting value of the $\mathrm{k}^{\text {th }}$ accomplishment feature. In the current study, the weights are calculated by employing the PCA argued in Section 4.2. Yang et al. (2006) investigated that the GRG also specifies the level of impact that the comparability sequence can utilize over the reference sequence. Thus, if a particular comparability sequence is more significant than the other comparability sequences to the reference sequence, the GRG for that comparability sequence and reference sequence will be greater than other grey relational grades. In the present work corresponding weighting values i.e. $\varepsilon_{\mathrm{k}}$ are obtained from PCA methodology.

\subsection{Principal Component Analysis}

PCA is a statistical implement of multivariate nature to solve the challenge involved in multi-collinearity amongst the primary data possibly correlated variables into an array of values of uncorrelated variables. Initiated through Pearson in 1901, with expansion through Hotelling in 1933, it later became very popular as an instrument of experimental data examination for the creation of representations for prediction. The implementation of PCA is through Eigen value disintegration of a data covariance matrix or singular value disintegration of a data matrix. It is used for detecting configurations in data and conveying the data in such a way as to high point their likenesses and differences (Johnson and Wichern, 1998). The key gain of PCA is that as soon as the patterns in data have been recognized, the data can be compressed, i.e. through reducing the number of measurements, without much harm of data. The PCA technique is adapted for the present work to determine the weight by transforming the contents of Table 4 in matrix form which is a 16x2 matrix. This matrix is used to find out the correlation coefficient. The assortment of correlation coefficient has been found out employing the subsequent equation.

Represent the multi responses by matrix:

$$
X=\left[\begin{array}{ccc}
x_{1}(1) & \ldots & x_{1}(n) \\
\cdot & \cdot & \cdot \\
\cdot & \cdot & \cdot \\
\cdot & \cdot & \cdot \\
x_{m}(1) & \ldots & x_{m}(n)
\end{array}\right]
$$

Evaluate the correlation coefficient array:

$$
\begin{aligned}
& R_{j i}=\left(\frac{\operatorname{Cov}\left(z_{i}(j), z_{i}(l)\right)}{\sigma\left(z_{i}(j) \times z_{i}(l)\right)}\right) \\
& \mathrm{j}=1,2 \ldots \ldots . \mathrm{m} ; \mathrm{l}=1,2 \ldots \ldots \mathrm{n}
\end{aligned}
$$

Here $\operatorname{Cov}\left(z_{i}(j), z_{i}(l)\right)$ is the covariance of sequences $Z_{i}(j), Z_{i}(l)$ and $\sigma Z_{i}(j)$ is the standard deviation of sequence $Z_{i}(j)$ and $\sigma \mathrm{Z}_{i}(l)$ is the standard deviation of sequence $\mathrm{Z}_{i}(l)$.

After calculating correlation coefficient array, Eigen vectors and Eigen values are calculated using following Eq. (8)

$$
\left(R-\delta_{k} I_{M}\right) U_{i k}=0
$$

Here, $\sum_{k=1}^{n} \delta_{k}=n \quad$ for $\mathrm{k}=1,2,3 \ldots . . n$ 
$U_{i k}=\left[\begin{array}{lllll}C_{k 1} & C_{k 2} & \ldots & C_{k 3}\end{array}\right]^{T}$ is the Eigen vectors corresponding to the Eigen value $\delta_{k}$. The Eigen values corresponding Eigen vectors are listed in Table 6 along with explained variation. The Eigen vectors and Eigen values are further used to find principal components by using following Eq. (9)

$$
X_{m k}=\sum_{i=1}^{n} Y_{m}(i) \cdot U_{i k}
$$

Here, $X_{m k}$ is called the $k^{\text {th }}$ principal component. Eigenvalues are aligned in descending order with respect to the variance.

Table 4: Response Table for Normalized (Ra, Rz), GRC and GRG

\begin{tabular}{cccccc}
\hline Trial & Normalized & Normalized & Grey Relational Coefficient(GRC) & Grey Relational \\
No. & $\mathrm{Ra}$ & $\mathrm{Rz}$ & $\mathrm{Ra}$ & $\mathrm{Rz}$ & 0.333 \\
1 & 0.194 & 0.000 & 0.383 & 0.385 & 0.358 \\
2 & 0.444 & 0.201 & 0.473 & 0.388 & 0.429 \\
3 & 0.000 & 0.212 & 0.333 & 0.505 & 0.753 \\
4 & 1.000 & 0.511 & 1.000 & 0.509 & 0.446 \\
5 & 0.194 & 0.519 & 0.383 & 0.723 & 0.598 \\
6 & 0.444 & 0.808 & 0.473 & 0.483 & 0.408 \\
7 & 0.000 & 0.465 & 0.333 & 0.706 & 0.853 \\
8 & 1.000 & 0.792 & 1.000 & 0.644 & 0.810 \\
9 & 0.988 & 0.723 & 0.976 & 0.666 & 0.636 \\
10 & 0.675 & 0.749 & 0.606 & 0.861 & 0.654 \\
11 & 0.381 & 0.919 & 0.447 & 1.008 & $0.878 *$ \\
12 & 0.831 & 1.004 & 0.748 & 0.685 & 0.830 \\
13 & 0.988 & 0.770 & 0.976 & 0.656 & 0.631 \\
14 & 0.675 & 0.738 & 0.606 & 0.691 & 0.569 \\
15 & 0.381 & 0.777 & 0.447 & 0.767 & 0.758 \\
16 & 0.831 & 0.849 & 0.748 & \\
\hline
\end{tabular}

*The calculation in the above table are based on the methodology as described in the optimization steps $4.1 \& 4.2$

\section{Optimization of Responses}

The square of the Eigen value vectors in line with the primary principal component stands for the involvement of the corresponding accomplishment feature to the principal component. The involvement of accomplishment features is revealed in Table 7. These involvements are signified by $0.5,0.5$ for Ra and Rz correspondingly. In addition, the variance contribution for the premier principal component featuring the four commplishment features is as elevated as $70.2 \%$ and revealed in Table 5. For this reason, in this investigation, the weighting values of the associated accomplishment feature are 0.5 and 0.5 respectively. Based on Eq. (5) the values of GRG are revealed in Table 4. Consequently, the optimization design has been carried out by means of single GRGs instead of the complex accomplishment features. Along with the achieved experimental design, it is evidently noticed from Table 4 that the CNC turning parametric location of experiment No. (12) exhibits the utmost GRG. Thus, $12^{\text {th }}$ experiment offers the superior multiperformance features amongst the sixteen experiments.

Table 5: The Eigen values and explained variation for principal components

\begin{tabular}{ccc}
\hline Principal Component & Eigen value & Explained Variation (\%) \\
First & 1.405 & 0.702 \\
Second & 0.595 & 0.298 \\
\hline
\end{tabular}

Eigen vector corresponds to largest value of explained variation will be the first principal component as tabulated in Table 6 .

Table 6: The Eigenvectors for Principal Component

\begin{tabular}{ccc}
\hline Performance Characteristics & First Principal Component & Second Principal Component \\
$\mathrm{Ra}$ & 0.707 & 0.707 \\
$\mathrm{Rz}$ & 0.707 & -0.707 \\
\hline & & \\
Table 7: The Contribution of each individual performance characteristics for the principal component \\
\hline Performance Characteristics & Contribution \\
$\mathrm{Ra}$ & 0.5 \\
$\mathrm{Rz}$ & 0.5 \\
\hline
\end{tabular}




\section{Analysis of Variance (ANOVA)}

The analysis is done with the help of software Design Expert 6.0.8. In the present study, we used ANOVA to calculate the most favourable mixture of process parameters extra precisely through studying the corresponding priority of process parameters. Table 8 represents the outcome of ANOVA for GRG. The model's fit was calculated with ANOVA, showcasing the influences of the representation that were statistically imperative for a confidence level of $95 \%$ (p-value $<0.05$ ), and those that were not statistically imperative (Siebertz et al., 2010). The complete-factorial designs were rooted in the statistical examinations, the prediction, precision and the efficiency. It is observed from the ANOVA Table, Percentage contribution of coolant (30.87\%) was found to be the major factor affecting the Response performance, whereas the SS (15.33\%) found to be second influential factor followed by FR $(3.06 \%)$ and DoC $(0.40 \%)$. Parameters are significantly different are decided statically by the F-Test. A larger F value shows the greater impact on the machining performance characteristics. Larger F-values are observed for coolant as 149.22, spindle speed as 74.14 and FR as 15.03 respectively.

Table 8: ANOVA Result of GRG with SS, FR, Doc and Coolant

\begin{tabular}{ccccccc}
\hline Source & DF & $\begin{array}{c}\text { Sum of } \\
\text { Squares }\end{array}$ & $\begin{array}{c}\text { Mean } \\
\text { Square }\end{array}$ & F-Value & P-Value & (PC) \\
Model & 10 & 0.484 & 0.048 & 47.550 & 0.0003 & 98.97 \\
SS(A) & 1 & 0.075 & 0.075 & 74.140 & 0.0003 & 15.33 \\
FR(B) & 1 & 0.015 & 0.015 & 15.030 & 0.0112 & 3.06 \\
Doc(C) & 1 & 0.002 & 0.002 & 2.860 & 0.151 & 0.40 \\
Coolant(D) & 1 & 0.151 & 0.151 & 149.22 & 0.0001 & 30.87 \\
AB & 1 & 0.122 & 0.122 & 120.07 & 0.0001 & 24.94 \\
AC & 1 & 0.0003 & 0.0003 & 0.330 & 0.591 & 0.06 \\
AD & 1 & 0.0651 & 0.651 & 63.96 & 0.0005 & 13.31 \\
BC & 1 & 0.007 & 0.0068 & 6.68 & 0.049 & 1.43 \\
BD & 1 & 0.0218 & 0.0218 & 21.50 & 0.006 & 4.45 \\
CD & 1 & 0.022 & 0.022 & 21.68 & 0.006 & 4.49 \\
Residual & 5 & 0.005 & 0.001 & & & \\
Cor Total & 15 & 0.489 & & & & \\
\hline
\end{tabular}

Model Summary

$\begin{array}{lccc}\text { S } & \text { R-sq. } & \text { R-sq. (adj) } & \text { R-sq. (pred) } \\ 0.0319076 & 98.96 \% & 96.88 \% & 89.34 \%\end{array}$

Moreover, the attained regression coefficients $\mathrm{R}^{2}$ (adj.) and $\mathrm{R}^{2}$ (pred.) (Davim et al., 2008) are respectively of $96.88 \%$ and $89.34 \%$ for GRG, ascertaining an outstanding match for the association flanked by the process parameters as well as the studied machining measure.

\section{Result and Discussion}

We consider SS, FR, DoC and Coolant (Dry/Wet Condition) as our input parameters and SR, Ra and Rz as our responses. The experimental data is examined by applying the GRA-PCA approach to establish the most advantageous mixture of machining parameters that SR, Ra and Rz are minimum at high SS and minimum FR \& Doc with Coolant. Here, for SR, Ra and Rz, lowerthe-better criterion has been carried out. Finally, GRG for every trial is calculated and is given in Table 4. The superior process parameters (A2B2C1D2) are established, which means on $1150 \mathrm{rpm} \mathrm{SS}, 56 \mathrm{~mm} / \mathrm{min} \mathrm{FR}, 0.36 \mathrm{~mm}$ DoC with Coolant.

\section{Response Table for the Grey Relational Grade (GRG)}

The response table in utilised to compute the average GRG for every parametric grade. It could be notice from Table 9 that the highest GRG for the factors A, B, C as well as D corresponds to levels 2, 2, 2 and 2 correspondingly. Consequently, A2B2C2D2 is 
the optimal parametric combination for the process of the CNC Turning. In addition, it was noted from the last column of the response table that the largely substantial response parameter that influences the accomplishment of the CNC Turning is the Coolant by means of the utmost disparity of GRG worth of 0.1949 after that 0.1374 for SS, 0.0619 for FR and 0.0270 for Doc as provided in Table 9.

Table 9: Response Table for the GRG

\begin{tabular}{|c|c|c|c|c|c|}
\hline Symbol & $\begin{array}{c}\text { CNC Turning } \\
\text { Parameter }\end{array}$ & Level 1 & Level 2 & Max - Min & Rank \\
\hline A & SS & 0.5545 & $0.6919^{*}$ & 0.1374 & 2 \\
\hline B & FR & 0.5923 & $0.6542^{*}$ & 0.0619 & 3 \\
\hline C & Doc & 0.6097 & $0.6367^{*}$ & 0.0270 & 4 \\
\hline D & Coolant & 0.5258 & $0.7207^{*}$ & 0.1949 & 1 \\
\hline
\end{tabular}

* Optimum Level

\section{Comparison of proposed method with additional method}

With the intention of verifying the proficiency of the put forward approach, very similar group of investigational data is employed to execute optimization employing the PCA approach as well as the GRA technique. The outcome of this jointly by means of the current GRA-PCA technique is revealed in Table10. The Table 10 reveals that decrease in Ra through $65.80 \%$, as well as decrease in $\mathrm{Rz}$ through $80.79 \%$ were noted whilst machining at the current GRA-PCA optimal parametric situation alongside the PCA optimal parametric situation. Likewise, as we weigh against the GRA optimal location it is established that Ra is condensed through $2.93 \%$ and decrease in Rz by $1.43 \%$ correspondingly. For this reason, GRA-PCA for the optimization of manifold-response problems is an extremely important hybrid technique.

Table 10: Comparison with additional method

\begin{tabular}{lllllc}
\hline & \multicolumn{3}{c}{ Optimal results with } & & \multicolumn{2}{c}{$\begin{array}{l}\text { Enhancement } \\
\text { technique } \\
\text { (GRA-PCA) weighed against }\end{array}$} \\
& PCA & GRA & GRA-PCA & PCA (\%) & GRA (\%) \\
Factor level & A1B1C1D1 & A2B2C2D2 & A2B2C2D2 & & \\
$\operatorname{Ra}(\mu \mathrm{m})$ & 1.550 & 0.546 & 0.530 & 65.80 & 2.93 \\
$\operatorname{Rz}(\mu \mathrm{m})$ & 24.990 & 4.870 & 4.80 & 80.79 & 1.43 \\
\hline
\end{tabular}

\section{Conclusion}

The GRA-PCA optimization technique was used to obtain optimum cutting condition during CNC Turning of AA 6463.Results was analyzed using ANOVA. The subsequent specific conclusions are described from the experimental results-

- The present research gives the result that GRA-PCA methodology optimized the SR Characteristic.

- Percentage involvement of each respective quality characteristic for the principal component is 0.5 for Ra and 0.5 for Rz.

- Optimal combination of the process parameters for the SR characteristics of the CNC Turning is A2B2C1D2.

- Quantitative involvements of the different factors are $15.33 \%$ of SS, 3.06\% of FR, $0.40 \%$ of Doc and $30.87 \%$ of coolant respectively.

- It is found that Coolant has the significant influence on the performance characteristics after that SS, FR and DoC.

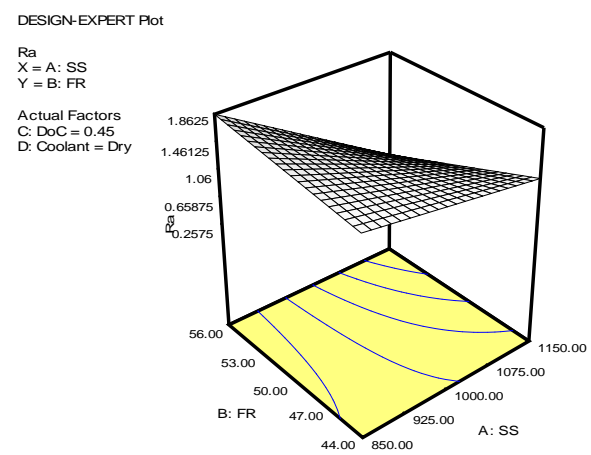

Figure 2: Surface Roughness Ra w.r.t. SS and FR 


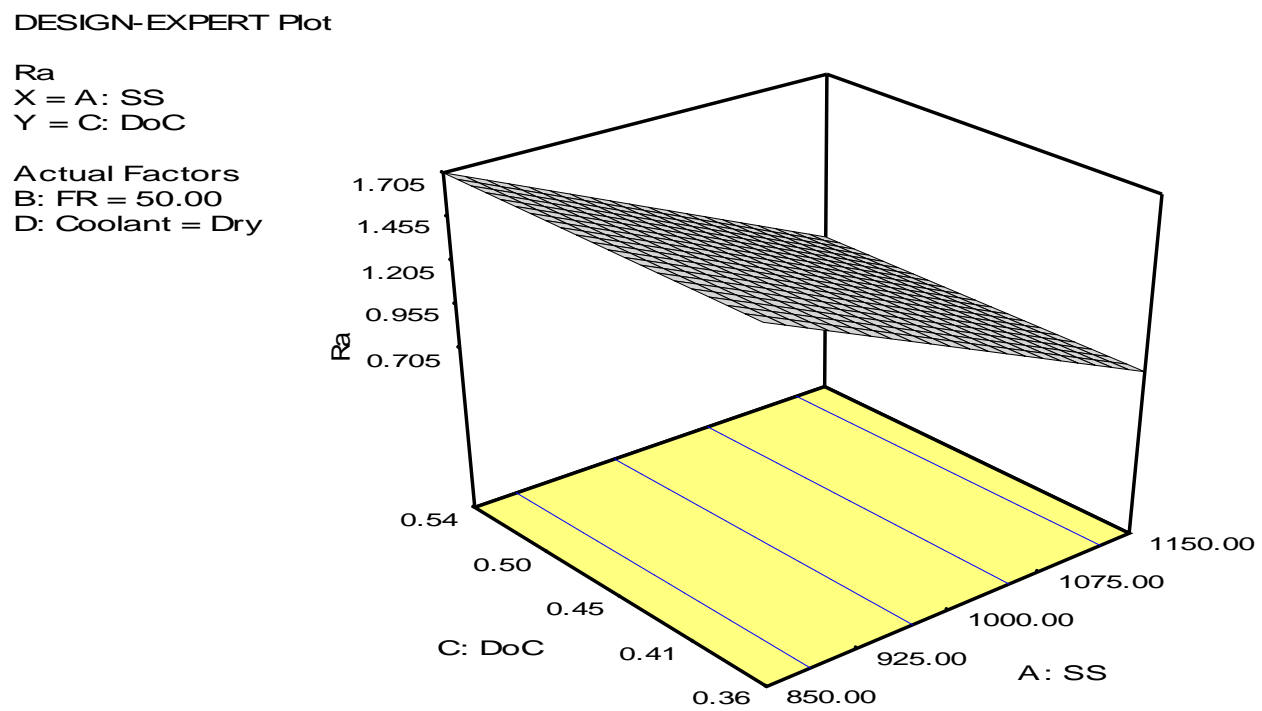

Figure 3: Surface Roughness Ra w.r.t. SS and DoC

\section{DESIGN-EXPERT Plot}

$\mathrm{Ra}$

$X=B: F R$

$Y=C: D o C$

Actual Factors

A: $S S=1000.00$

D: Coolant $=$ Dry

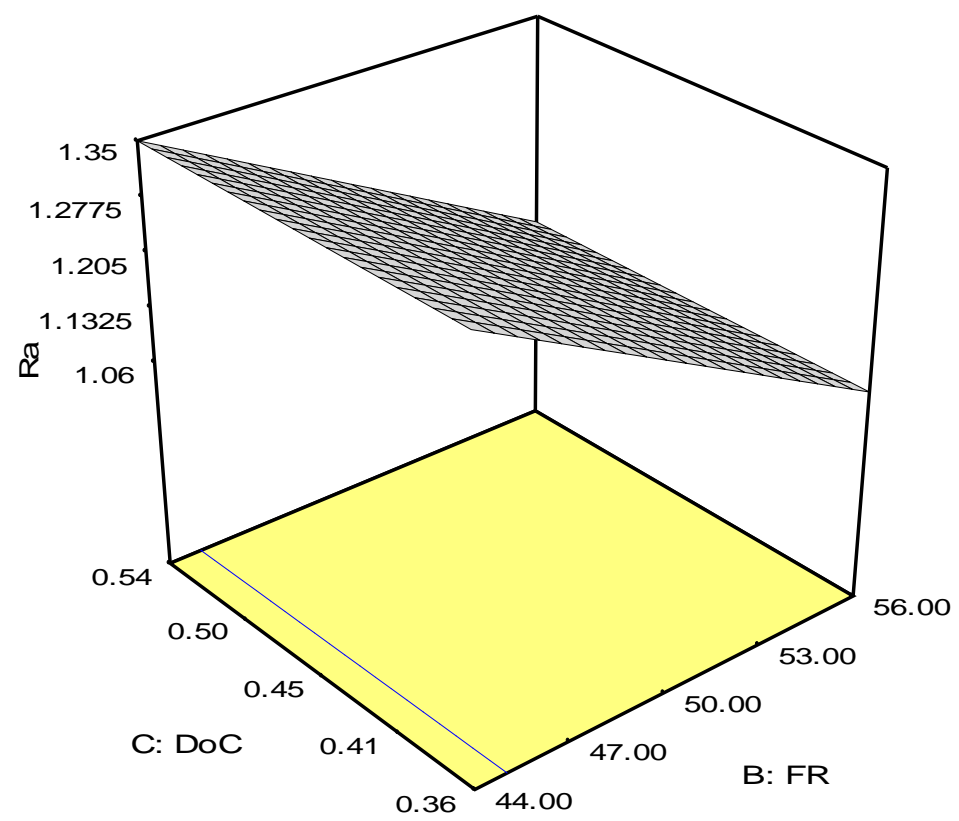

Figure 4: Surface Roughness Ra w.r.t. FR and DoC 


\section{DESIGN-EXPERT Plot}

$\mathrm{Rz}$

$X=A: S S$

$\mathrm{Y}=\mathrm{B}: \mathrm{FR}$

Actual Factors

$\mathrm{C}: \mathrm{DoC}=0.45$

D: Coolant $=$ Dry

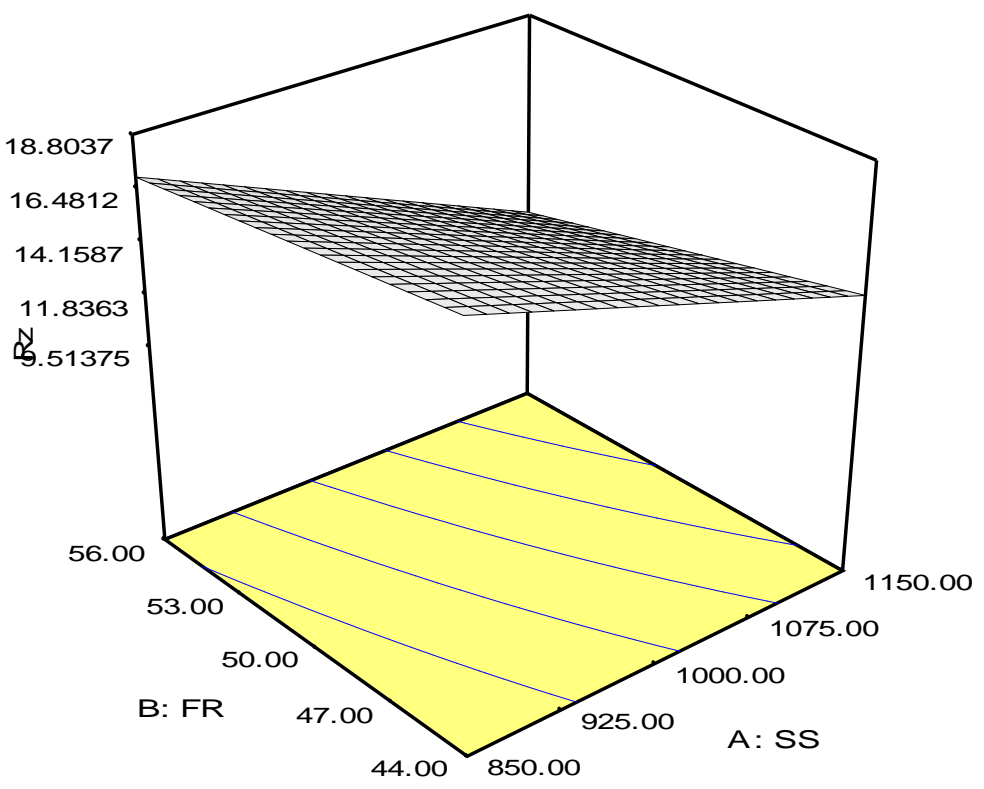

Figure 5: Surface Roughness Rz w.r.t. SS and FR

DESIGN-EXPERT Plot

$\mathrm{Rz}$

$X=B: F R$

$\mathrm{Y}=\mathrm{C}: \mathrm{DOC}$

Actual Factors

A : $S S=1000.00$

D: Coolant $=$ Dry

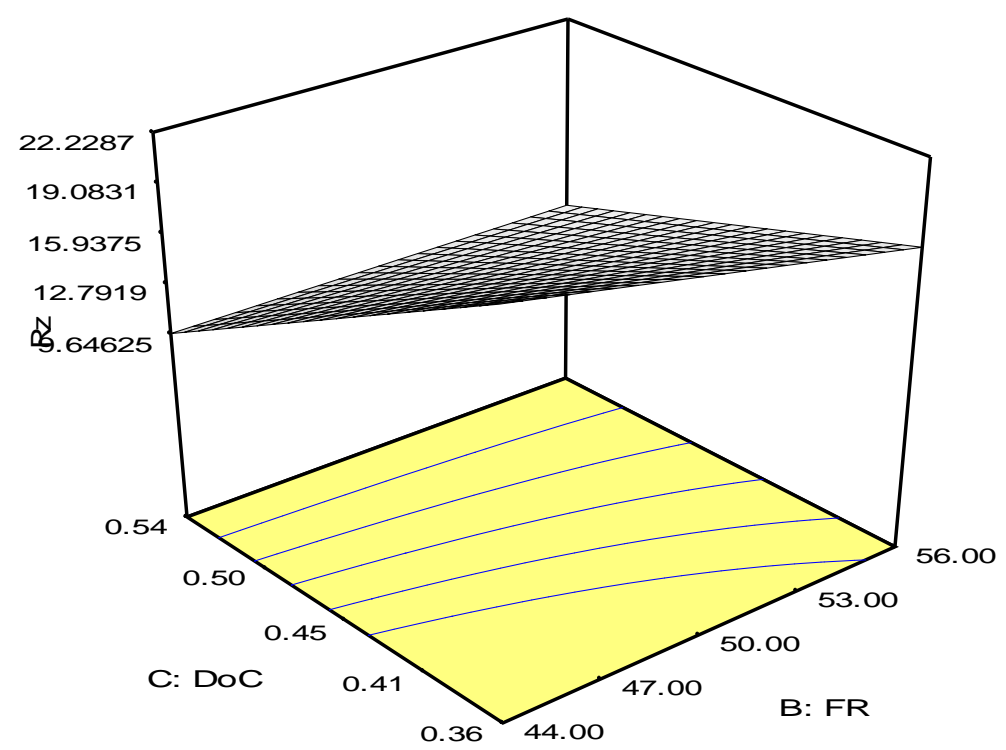

Figure 6: Surface Roughness Rz w.r.t. FR and DoC 


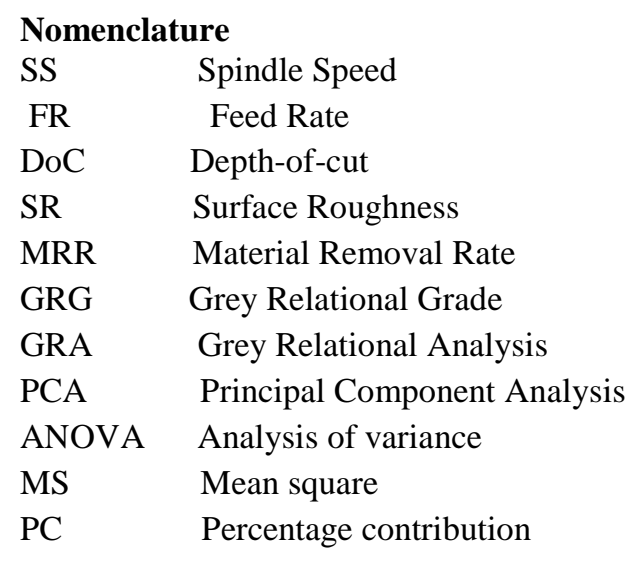

$\begin{array}{ll}\text { Symbols } & \\ \Delta_{0, \mathrm{i}}(\mathrm{k}) & \text { Absolute deviation sequence } \\ \beta & \text { Grey relational coefficient } \\ \gamma & \text { Grey Relational Grade } \\ \delta & \text { Eigen values } \\ U_{i k} & \text { Eigen vectors }\end{array}$

\section{Acknowledgment}

Authors sincerely thank to the Director, MITS, Gwalior (M.P.) India for the providing facilities to carry out this research work and the technical support provided by "Central Institute of Plastics Engineering \& Technology (CIPET), Gwalior (M.P.) India.

\section{References}

Alagarsamy S.V., Raveendran.P., Arockia V. S. S. and Tamil V. S., 2016. Optimization of machining parameters for turning of aluminium alloy 7075 using taguchi method, International Research Journal of Engineering and Technology, Vol. 3, pp. 316- 322.

Antony J., 2000. Multi-Response Optimization In Industrial Experiments Using Taguchi'S quality loss function and principal component analysis, Quality and Reliability Engineering International, Vol.16 pp. 3-8.

Arbizu I.P. and Luis Pérez C.J., 2003. Surface roughness prediction by factorial design of experiments in turning process, Journal of Materials Processing Technology, Vol.144, pp. 390-396.

Benardos P. G. and Vosniakos G., 2003. Predicting surface roughness in machining : a review, International Journal of Machine Tools \& Manufacture, Vol. 43, pp. 833-844.

Boothroyd G., and Knight W.A., 1989. Fundamentals of Machining and Machine Tools, Marcel-Dekker, New York.

Chaurasia V. K., Kasdekar D. K., Shivhare V., 2016. Development of Artificial Intelligence Model for the Prediction of MRR in Turning, International Journal of Hybrid Information Technology, Vol.9, No.2, pp.75-82.

Chaurasia V. K., Kasdekar D. K., Parashar V., 2015. Analysis of the Influence and Artificial Intelligence Model to Predict MRR in CNC Turning, International Journal of Advances in Science and Technology, Vol.7, pp.24-31.

Chinchanikar S. and Choudhury S. K., 2014. Machining of hardened steel: Experimental investigations, performance modeling and cooling techniques: A review, International Journal of Machine Tools and Manufacture, doi:10.1016/j.jimachtools.2014.11.002.

Chang. C., Tsai C. and Chen L., 2003. Applying grey relational analysis to the decathlon evaluation model, International Journal of Computer and Internet Management, Vol. 11, No. 3, pp.54-62.

Das S., Doley R, Kashyap S. and Pathak H., 2016. Cutting process optimisation and modelling in dry turning of AISI H13 tool steel with brazed carbide tip, International Journal of Precision Technology, Vol. 6, No.1, pp.42-60.

Davim J. P., 2003. Design of optimization of cutting parameters for turning metal matrix composites based on the orthogonal arrays, Journal of Materials Processing Technology, Vol.132, pp. 340-344.

Davim JP, Gaitonde V.N. and Karnik S.R., 2008. Investigations into the effect of cutting conditions on surface roughness in turning of free machining steel by ANN models, Journal of Material Processing Technology, Vol. 205, No. (1-3), pp. 16-23.

Deng JL., 1989. Introduction to Grey System Theory, Journal of Grey System, Vol.1, No.1, pp. 1-24.

Fung CP., 2003. Manufacturing process optimization for wear property of fiber- reinforced polbutylene terephthalate composites with grey relation analysis, Wear, pp. 298-306. 
Groover M.P., 1996. Fundamentals of Modern Manufacturing-Materials Processing and Systems, Prentice-Hall, Englewood Cliffs.

Guesser W.L., Pereira F. S. and Boehs L., 2016. Surface changes during turning of grey cast iron, International Journal of Machining and Machinability of Materials, Vol. 18, No. 3, pp.313-323.

Haq A. N., Marimuthu P. and Jeyapaul R., 2008. Multi response optimization of machining parameters of drilling Al / SiC metal matrix composite using grey relational analysis in the Taguchi method, International Journal of Advanced Manufacturing Technology, Vol.37, pp. 250-255.

Heidari M. and Yan J., 2017. Fundamental characteristics of material removal and surface formation in diamond turning of porous carbon, Internationa Journal of Additive and Subtractive Materials Manufacturing, Vol. 1, No. 1, pp. 23- 41.

Huang J.T. and Liao Y.S., 2003. Optimization of machining parameters of Wire-EDM based on grey relational and statistical analysis, International Journal of Production Research, Vol.41, No.8, pp.1707-1720.

Jeyapaul R., Shahabudeen p. and Krishnaiah k., 2005. Quality management research by considering multi-response problems in the Taguchi method - a review, International Journal of Advanced Manufacturing Technology, vol. 26, pp. 1331-1337.

Johnson RA. and Wichern DW., 1998. Applied multivariate statistical analysis. Prentice-Hall, Englewood Cliffs.

Kaladhar M., Subbaiah K.V., Rao K. N. and Rao Ch. S., 2010. Optimization of process parameters in turning of AISI 202 Stainless Steel, ARPN Journal of Engineering and Applied Sciences, Vol.5, No. 9, pp.79-87.

Kasdekar D K. and Parashar V., 2017. Principal Component Analysis to Optimize the ECM Parameters of Aluminium Alloy, $7^{\text {th }}$ International Conference on Materials Processing and Characterization, ICMPC, India.

Kasman S., 2013. Multi-response optimization using the Taguchi- based grey relational analysis: a case study for dissimilar friction stir butt welding of AA6082-T6/AA5754-H111, International Journal of Advanced Manufacturing Technology, Vol. 68 , pp. 805-815.

Liao H.C., 2006. Multi-response optimization using weighted principal component, International Journal of Advanced Manufacturing Technology, Vol.27, pp. 720-725.

Lin C.L., 2004. Use of the Taguchi method and grey relational analysis to optimize turning operations with multiple performance Characteristics, Materials and Manufacturing Processes, Vol. 19, No. 2, pp. 209-220.

Liu D., Huang C., Wang J., Zhu H., Yao P. and Liu Z., 2014. Modeling and optimization of operating parameters for abrasive water jet turning alumina ceramics using response surface methodology combined with Box - Behnken design, Ceramics International, Vol.40, No.6, pp. 7899-7908.

Mukherjee S., Kamal A . and Kumar K., 2014. Optimization of material removal rate during turning of SAE 1020 material in CNC lathe using taguchi technique, Procedia Engineering, Vol.97, pp.29-35.

Nian C. Y., Yang W. H. and Tarng Y. S., 1999. Optimization of turning operations with multiple performance characteristics, Journal of Materials Processing Technology, Vol.95, pp. 90-96.

Ranganath M. S. and Mishra R. S., 2015.Optimization of surface roughness in CNC turning of aluminium 6061 using taguchi techniques, International Journal of Modern Engineering Research, Vol.5, pp.42-50.

Raykar S. J., D'Addona D.M., Mane A. M., 2015. Multi-objective optimization of high speed turning of Al 7075 using grey relational analysis, Procedia CIRP, Vol. 33, pp. 293-298.

Ribeiro JS., Te' ofilo RF.,Augusto F. and Ferreira MMC., 2010. Simultaneous optimization of the microextraction of coffee volatiles using response surface methodology and principal component analysis, Chemometr Intelligent Laboratory System, Vol. 102, pp. 45- 52.

Routara B. C. and Mohanty S. D., 2010. Combined quality loss ( CQL ) concept in WPCA-based Taguchi philosophy for optimization of multiple surface quality characteristics of UNS C34000 brass in cylindrical grinding grinding, International

Journal of Advanced Manufacturing Technology, Vol. 51, pp. 135-143.

Salimiasl A. and Özdemir A. 2016. Modelling of the cutting forces in turning process for a new tool, International Journal of Mechatronics and Manufacturing Systems, Vol. 9, No. 2, pp.160-172.

Siddiquee A.N., Khan Z.A. and Mallick Z., 2010. Grey relational analysis coupled with principal component analysis for optimization design of the process parameters in in-feed ceterless cylindrical grinding, International Journal of Advanced Manufacturing Technology, Vol.46, pp. 983-992.

Singh B. J. and Sodhi H. S., 2014. Parametric optimisation of CNC turning for Al-7020 with RSM, International Journal of Operational Research, Vol. 20, No. 2, pp.180-206.

Saini S.K., and Pradhan S.K., 2014. Optimization of Multi-Objective Response during CNC Turning using Taguchi-Fuzzy Application, Procedia Engineering, Vol.97, pp. 141-149.

Senthilkumar N., Selvakumar V. and Tamizharasan T., 2016. Optimization and Performance Analysis of Uncoated and coated Carbide Inserts During Hard Turning AISI D2 Steel Using Hybrid GRA-PCA Technique, Applied Mechanics and Materials, Vol.852, pp. 151-159.

Siebertz D., Bebber Van. And Hochkirchen T., 2010. Design of Experiments (DOE), Springer Heidelberg Dordrecht London New York.

Singarvel B., Selvaraj T. and Jeyapaul R., 2014. Multi Objective Optimization in Turning of EN25 Steel Using Taguchi Based Concept Coupled With Principal Component Analysis, Procedia Engineering,Vol. 9, pp. 158-165. 
Su C., and Ton L., 1997. Multi-response robust design by principal component analysis, Total Quality Management, Vol. 8, No. 6, pp. 37-41.

Tzeng C., Lin Y., Yang Y. and Jeng. M., 2008. Optimization of turning operations with multiple performance characteristics Using the Taguchi method and Grey relational analysis, Journal of Materials Processing Technology, Vol.209, pp.2753-2759.

Wu F., and Chyu C. C., 2004. Optimization of Correlated Multiple Quality Characteristics Robust Design Using Principal Component Analysis, Journal of Manujhcturing Systems, Vol. 23,No. 2, pp.134-143.

Yang Y.Y., Shie J.R. and Huang C.H., 2006. Optimization of Dry Machining Parameters for High Purity Graphite in End-Milling Process, Materials and Manufacturing Processes, Vol. 21, pp. 832-837

Yuan C., Zhai Q., Cao H. and Zhao X., 2014. Assessing application potential of clean energy supply for greenhouse gas emission mitigation: a case study on General Motors global manufacturing, Journal of Cleaner Production, Vol.75, pp.1-9.

\section{Biographical notes}

Suneel Kumar Rathore graduated in Mechanical Engineering from REWA Engineering College Rewa (M.P.), affiliated by Rajiv Gandhi Proudyogiki Vishwavidhyalaya Bhopal (M.P.), India in 2013.He is presently doing M. Tech in Production Engineering from Madhav Institute of Technology and Science, Gwalior (M.P).

Dr. Jyoti Vimal obtained her M. Tech degree in Mechanical Engineering in CAD/CAM from HBTI Kanpur (U.P.), India in 2006 and Ph.D. degree from MNNIT Allahabad (U.P.), India. He is currently working as Assistant Professor in Department of Mechanical Engineering, M.I.T.S., Gwalior, (India). His areas of interest are Evolutionary Algorithm and optimization Analysis, FEM analysis.

Prof. Dinesh K Kasdekar obtained his M. Tech degree in CIM from SATI Vidisha (M.P.), and Pursuing Ph.D. degree from MANIT Bhopal (M.P.), India. He is currently working as Assistant Professor in Department of Mechanical Engineering, M.I.T.S., Gwalior, (India). His areas of research are Evolutionary Algorithm and Optimization Techniques.

Received May 2017

Accepted May 2018

Final acceptance in revised form May 2018 